\title{
An instrument design for non-contact detection of biomolecules and minerals on Mars using fluorescence
}

\author{
Heather D Smith ${ }^{1,2^{*}}$, Christopher P McKay ${ }^{2}$, Andrew G Duncan ${ }^{3}$, Ronald C Sims ${ }^{1}$, Anne J Anderson ${ }^{4}$ \\ and Paul R Grossl ${ }^{5}$
}

\begin{abstract}
We discuss fluorescence as a method to detect polycyclic aromatic hydrocarbons and other organic molecules, as well as minerals on the surface of Mars. We present an instrument design that is adapted from the ChemCam instrument which is currently on the Mars Science Lander Rover Curiosity and thus most of the primary components are currently flight qualified for Mars surface operations, significantly reducing development costs. The major change compared to ChemCam is the frequency multipliers of the $1064 \mathrm{~nm}$ laser to wavelengths suitable for fluorescence excitation ( $266 \mathrm{~nm}, 355 \mathrm{~nm}$, and $532 \mathrm{~nm}$ ). We present fluorescence spectrum for a variety of organics and minerals relevant to the surface of Mars. Preliminary results show minerals already known on Mars, such as perchlorate, fluoresce strongest when excited by $355 \mathrm{~nm}$. Also we demonstrate that polycyclic aromatic hydrocarbons, such as those present in Martian meteorites, are highly fluorescent at wavelengths in the ultraviolet ( $266 \mathrm{~nm}, 355 \mathrm{~nm}$ ), but not as much in the visible $(532 \mathrm{~nm})$. We conclude that fluorescence can be an important method for Mars applications and standoff detection of organics and minerals. The instrument approach described in this paper builds on existing hardware and offers high scientific return for minimal cost for future missions.
\end{abstract}

\section{Introduction}

A practical difficulty with organic and biological analysis on Mars missions is getting to, and collecting, the sample. Rovers remotely operated from Earth can take many days to drive to a site and to collect a sample. For this reason there is considerable interest in selection of target samples - both rock and dirt - from a distance of several meters.

The current method for non-contact detection on the Mars Science Laboratory (MSL) is ChemCam. ChemCam employs Laser-Induced Breakdown Spectrometer (LIBS) and can accomplish elemental chemical determination [1]. ChemCam consists of two instruments: 1) a remote micro-imager (RMI) capable of $\mathrm{mm}$ resolution from meters away and 2) a laser-induced breakdown spectrograph (LIBS) capable of determining certain elemental concentrations as low as $10 \mathrm{ppm}$ [1]. The ChemCam

\footnotetext{
* Correspondence: hdsmith@aggiemail.usu.edu

'Department of Biological Engineering, Utah State University, Logan, UT, USA ${ }^{2}$ NASA Ames Research Center, Space Science Division, Moffett Field, CA, USA Full list of author information is available at the end of the article
}

instrument sits on the Curiosity rover mast 1.8 meters above the ground allowing for remote analysis at distances up to 9 meters [1]. The ChemCam instrumentation has achieved several technical breakthroughs including the first flight-qualified laser. All of the ChemCam hardware, including the excitation and emission systems, have achieved flight qualification, and are at Technical Readiness Level (TRL) 9 now that MSL is operating on the martian surface. A major addition in standoff detection would be the ability to detect low levels (ppm and less) of organics in rock and soil samples. Two methods are under consideration for this task: Raman spectroscopy and UV fluorescence. Standoff detection of organics by both Raman [2,3] and fluorescence [4] have been demonstrated in laboratory trials. In general, Raman spectroscopy provides better identification of organics than fluorescence while fluorescence provides a higher sensitivity to low levels of organics. In this paper we focus on fluorescence as a method to do stand-off detection of biological, organic, and mineralogical assays on future Mars missions. 
Characterization of targets via fluorescence involves both an excitation wavelength and an emission wavelength. The excitation that results in fluorescence occurs when a photon of the appropriate wavelength reaches, or excites, the target and the energy state of an electron is raised. As the energy dissipates, the electron cascades down to lower energy states. The energy released in this cascade is emitted as photons of wavelengths longer than the excitation wavelength due to the loss of energy required to raise the electron state.

Previous investigations have employed the use of native fluorescence for mineral identification, organics, and photosynthetic compounds for over 100 years [5-16]. One such investigation examined using native fluorescence spectra of chlorophyll a and other photosynthetic pigments in their natural environment using airborne assets was first reported by Hoge and Swift [5]. A more extensive investigation using various pigment-protein Macromolecules in the 480-560 spectral region demonstrated the capability of measuring a variety of photosynthetic pigments using native fluorescence [6]. More recent investigations measured the fluorescence of several photosynthetic pigments to determine the microbial community of photosynthetic organisms [15,16]. A few in-situ fluorescence instruments have been developed to identify biosignatures and are at various stages of flight technical readiness levels. These instruments are aimed at detecting microbes by adding a fluorescing reagent [17] or within a fairly uniform, low fluorescence material such as ice $[18,19]$ and in the ocean [20]. Work has begun to look at native fluorescence in soil as well [21]. These instruments provide a fluorescent method for detecting biomolecules and chemical organics.

In addition to detecting biomolecules and chemical organics, fluorescence can also be used as a tool for mineralogical identification [22] to aid in target selection. Many minerals are fluorescent when excited at certain excitation and emission wavelength combinations, for example, the mineral fluorite derives its name after this characteristic fluorescence property. Often in planetary applications spectral information requires information on the geological context before a mineral is identified. This does not diminish the utility of spectral data. Mineral and rock species identified on the surface of Mars include hematite, jarosite, olivine, phylosilicates, carbonates, perchlorate $\left(\mathrm{ClO}_{4}\right)$, basalts, and ice among others [23,24].

\section{Modified ChemCam Instrument}

The LIBS system that forms the core of ChemCam is a suitable starting point for future combined LIBS/Raman or LIBS/fluorescence instruments. Laser induced breakdown spectroscopy operates by heating/energizing the target surface producing a plasma. Elements are identified and their concentration determined based on the strength of atomic emission lines in the spectrum. ChemCam uses a $5 \mathrm{~ns}$ pulsed $1064 \mathrm{~nm}$ laser with a $15 \mathrm{hz}$ firing rate drawing $30 \mathrm{~mJ}$ per pulse to produce the plasma [1]. To capture the emission spectrum of the plasma, ChemCam has a Schmidt telescope to increase the light gathering power before feeding the signal into three spectrometers. The spectrometers are customized versions of off-the-shelf Ocean Optics HR2000 spectrometers, each designed to measure specific wavelengths of the emission spectra (240-336 nm, 380-470 nm, 500-800 nm respectively). In a typical application the signal is integrated over 75 laser pulses. The combined spectrometer detection ranges from ultra-violet (UV) $240 \mathrm{~nm}$ to red $800 \mathrm{~nm}$ [1].

The primary component of the ChemCam instrument that enables fluorescence assessment is the $1064 \mathrm{~nm}$ laser. This wavelength $(1064 \mathrm{~nm})$ is too long of a wavelength,

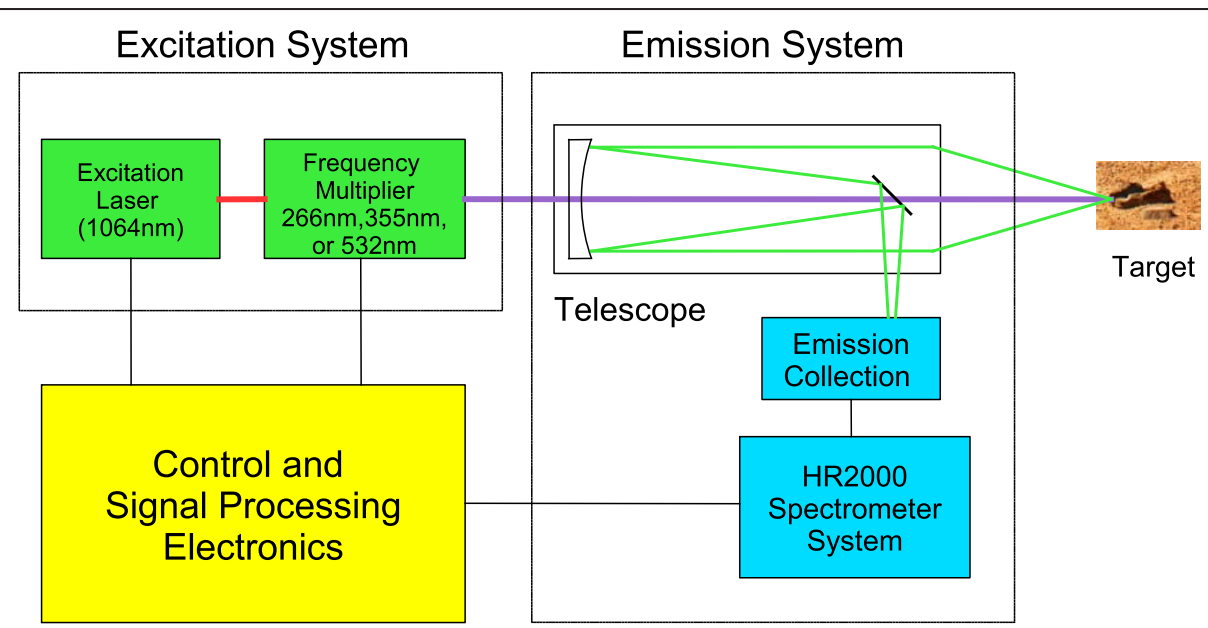

Figure 1 System level block diagram of the modified ChemCam instrument. Frequency multipliers are added to the excitation system for optimization of biomolecular, organic, and mineral flourescence detection. Diagram adapted from [1]. 


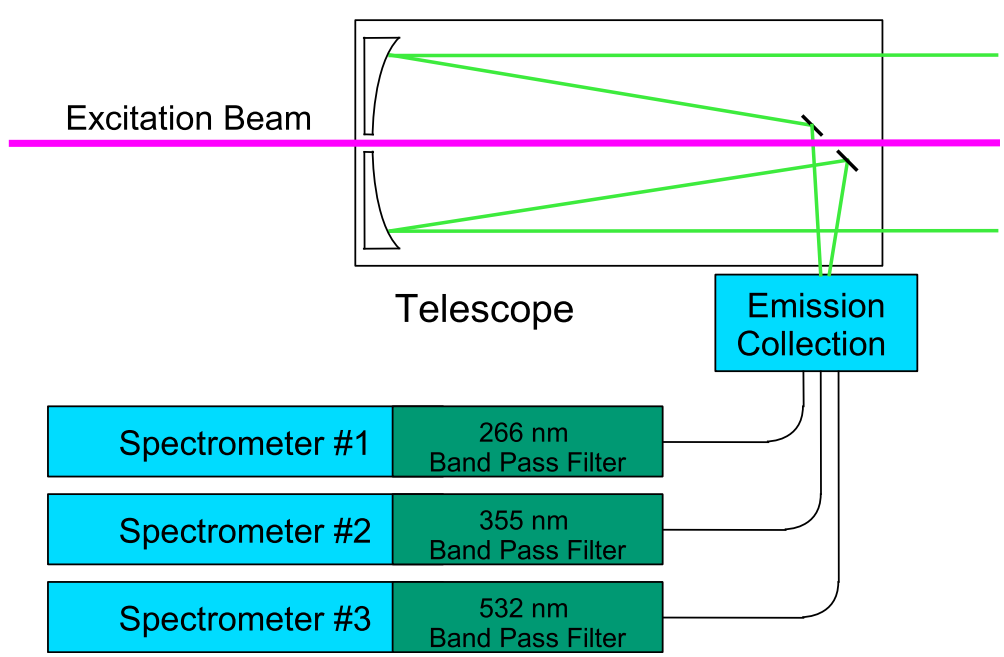

Figure 2 Emission Collection System enabling biomolecule, organics, and minerals detection by specific wavelength flourescence emission showing the appropriate filter blocks.

hence too low-energy to induce fluorescence. However with the aid of a frequency multiplier, irradiation can be produced at the three harmonic wavelengths, double, triple, and quadruple of the frequency of the original $1064 \mathrm{~nm}$ light, corresponding to wavelengths of $532 \mathrm{~nm}$, $355 \mathrm{~nm}$, and $266 \mathrm{~nm}$, respectively. Biological material, organics, and minerals fluoresce when excited at $266 \mathrm{~nm}$ and $355 \mathrm{~nm}$. Thus the main modification of the ChemCam excitation system to enable fluorescence is the addition of three interchangeable frequency multipliers. A flight- qualified mechanical drive train and control box used for the camera filter wheel, for example that used on board the Beagle 2 Lander [25,26] could rotate the frequency multipliers into position. Figure 1 is a system level block diagram of the new instrument.

The emission collection system has one main modification, the placement of a band pass notch filter in front of each of the three spectrometers. These filters block the excitation wavelengths allowing the natural fluorescence to pass through to the spectrograph. The emission collection

Table 1 Common organics (polycyclic aromatic hydrocarbons, PAH) of extraterrestrial origin (meteorites, interstellar medium (ISM)), and potiential biomolecules that could be on the surface of Mars, excitation and emission wavelength peaks, and reference

\begin{tabular}{|c|c|c|c|c|}
\hline Biomolecules & Description & Excitation $\lambda$ & Emission $\lambda$ & Reference \\
\hline$\overline{\text { ATP }}$ & ubiqitous metabolite & $280 \mathrm{~nm}$ & $420 \mathrm{~nm}$ & Katayama et al. [30] \\
\hline Phenaylanine & amino acid in ISM & $260 \mathrm{~nm}$ & $282 \mathrm{~nm}$ & Seaver et al. [31] \\
\hline $\mathrm{NADH}$ & ubiqitous metabolite & $350 \mathrm{~nm}$ & $460 \mathrm{~nm}$ & Richards-Kortum et al. [32] \\
\hline Tyrosine & amino acid in ISM & $275 \mathrm{~nm}$ & $304 \mathrm{~nm}$ & Nevin et al. [33] \\
\hline Tyrptophan & amino acid in ISM & $280 \mathrm{~nm}$ & $353 \mathrm{~nm}$ & Alimova et al. [34] \\
\hline \multicolumn{5}{|c|}{ Chemical organics } \\
\hline Benzopyrene & PAH in Mars meteorites & $383 \mathrm{~nm}$ & $435 \mathrm{~nm}$ & Kuijt et al. [35] \\
\hline Chrysene & PAH in Mars meteorites & $307 \mathrm{~nm}$ & $370 \mathrm{~nm}$ & Kuijt et al. [35] \\
\hline Napthalene & PAH in Mars meteorites & $275 \mathrm{~nm}$ & $344 \mathrm{~nm}$ & Kuijt et al. [35] \\
\hline Perylene & PAH in Mars meteorites & $280 \mathrm{~nm}$ & no peak & Pujari et al. [36] \\
\hline Perylene & & $440 \mathrm{~nm}$ & $472 \mathrm{~nm}$ & Wilson et al. [37] \\
\hline Phenanthrene & $\mathrm{PAH}$ in Mars meteorites & $280 \mathrm{~nm}$ & $410 \mathrm{~nm}$ & Pujari et al. [36] \\
\hline Phenanthrene & & $306 \mathrm{~nm}$ & $361 \mathrm{~nm}$ & Kuijt et al. [35] \\
\hline Pyrene & PAH in Mars meteorites & $347 \mathrm{~nm}$ & $387 \mathrm{~nm}$ & Kuijt et al. [35] \\
\hline Pyrene & & $342 \mathrm{~nm}$ & $376,396 \mathrm{~nm}$ & Wilson et al. [37] \\
\hline
\end{tabular}




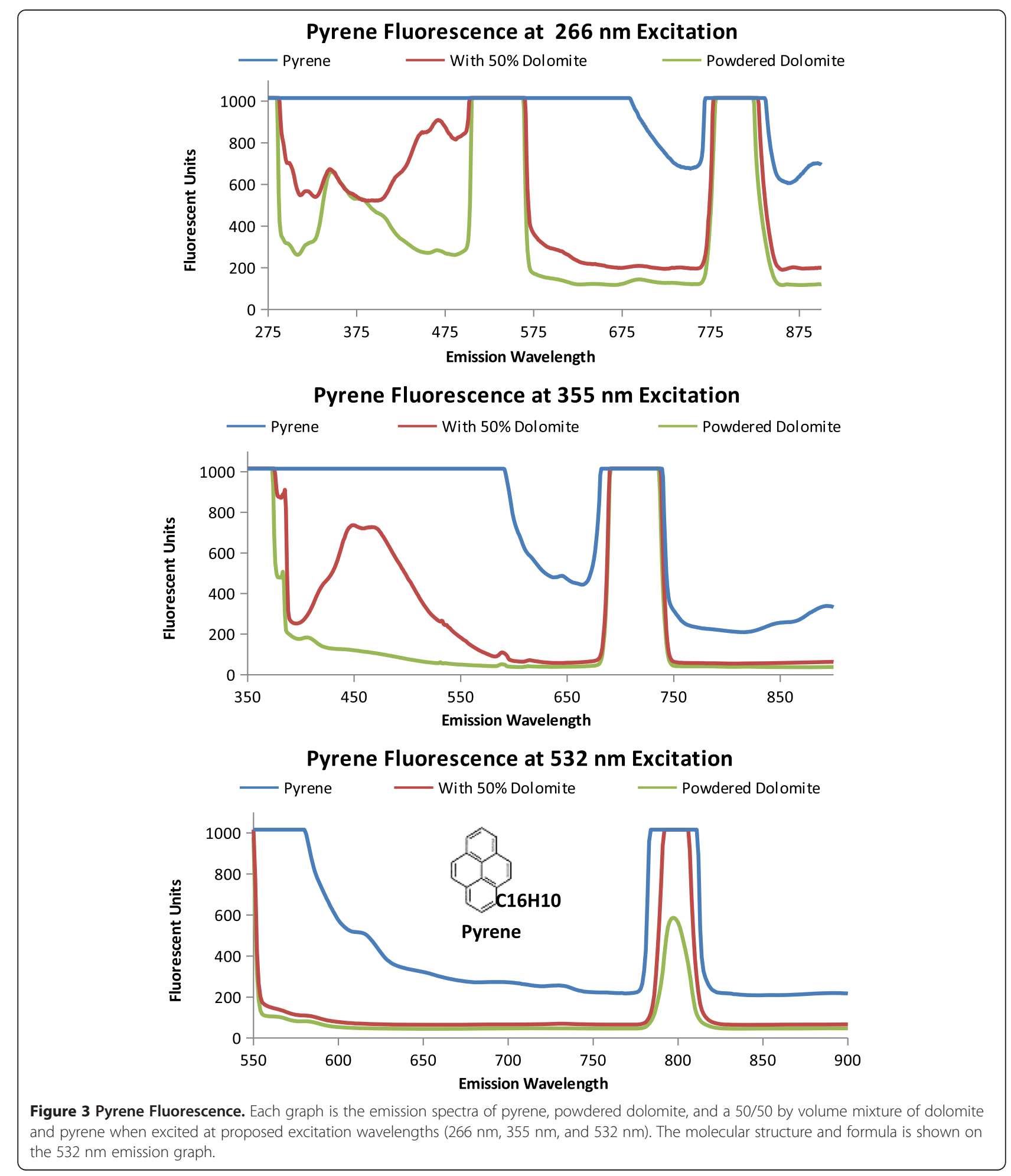

system (Figure 2) will employ the Schmidt telescope, the original three ChemCam spectrographs, and the addition of three notch narrow band pass filters $(266 \mathrm{~nm}, 355 \mathrm{~nm}$, and $532 \mathrm{~nm}$ ). The only non-flight qualified hardware of the entire fluorescence instrument design are the frequency multipliers and the non-moving band pass notch filters as every other system component has been flight qualified. An estimate of these additional components is less than a kilogram of mass and in the tens of thousands of dollars. 


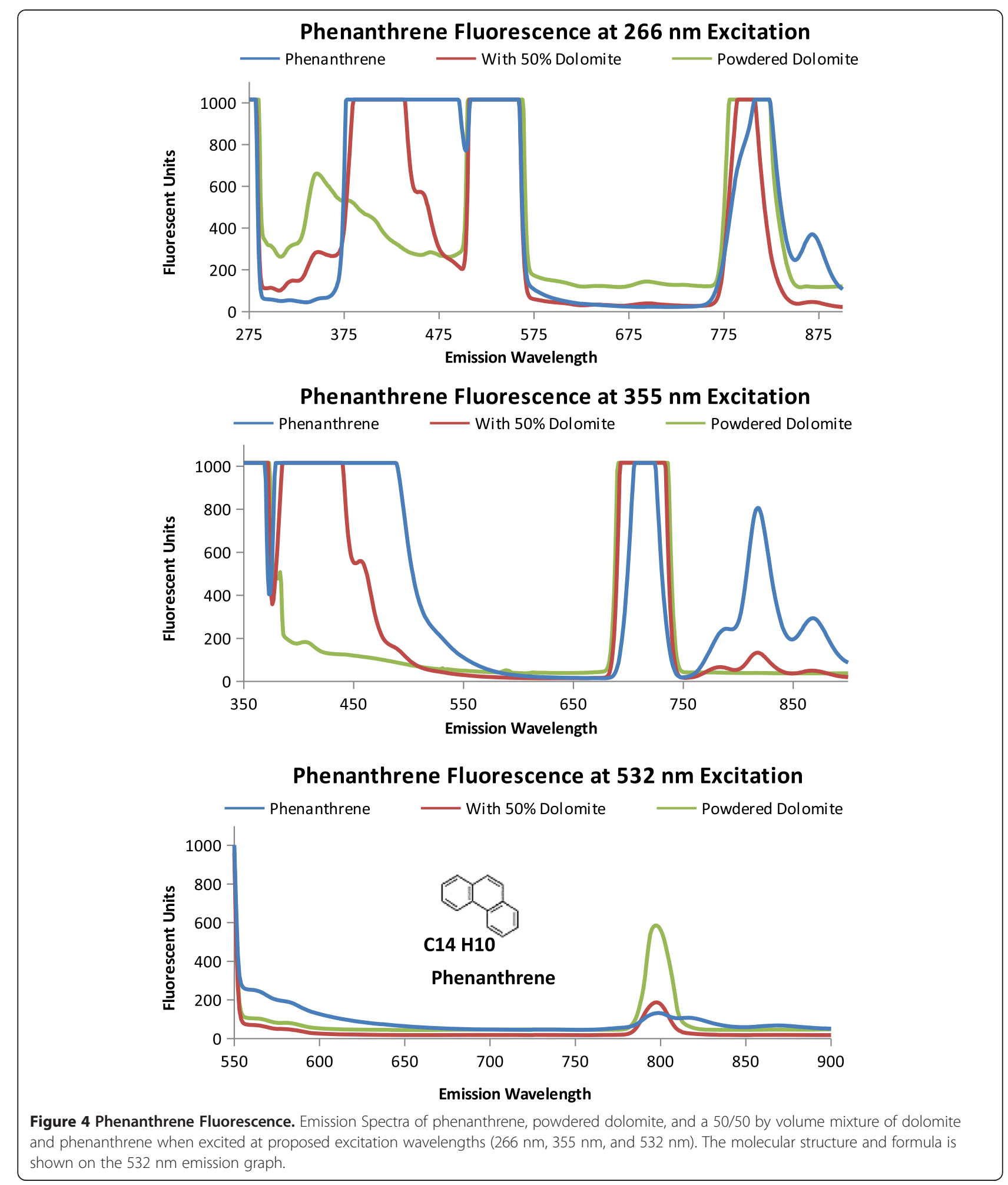

UV fluorescence of organics and minerals relevant to Mars Many organic molecules, particularly polycyclic aromatic hydrocarbons (PAHs) fluoresce (See Table 1). Polycyclic aromatic hydrocarbons have been found in Martian meteorites, and are the primary form of organic matter found in many meteorites [27]. Biomolecules occurring as amino acids have been detected in the interstellar medium (ISM) [28]. Hence, PAHs and amino acids are plausible 

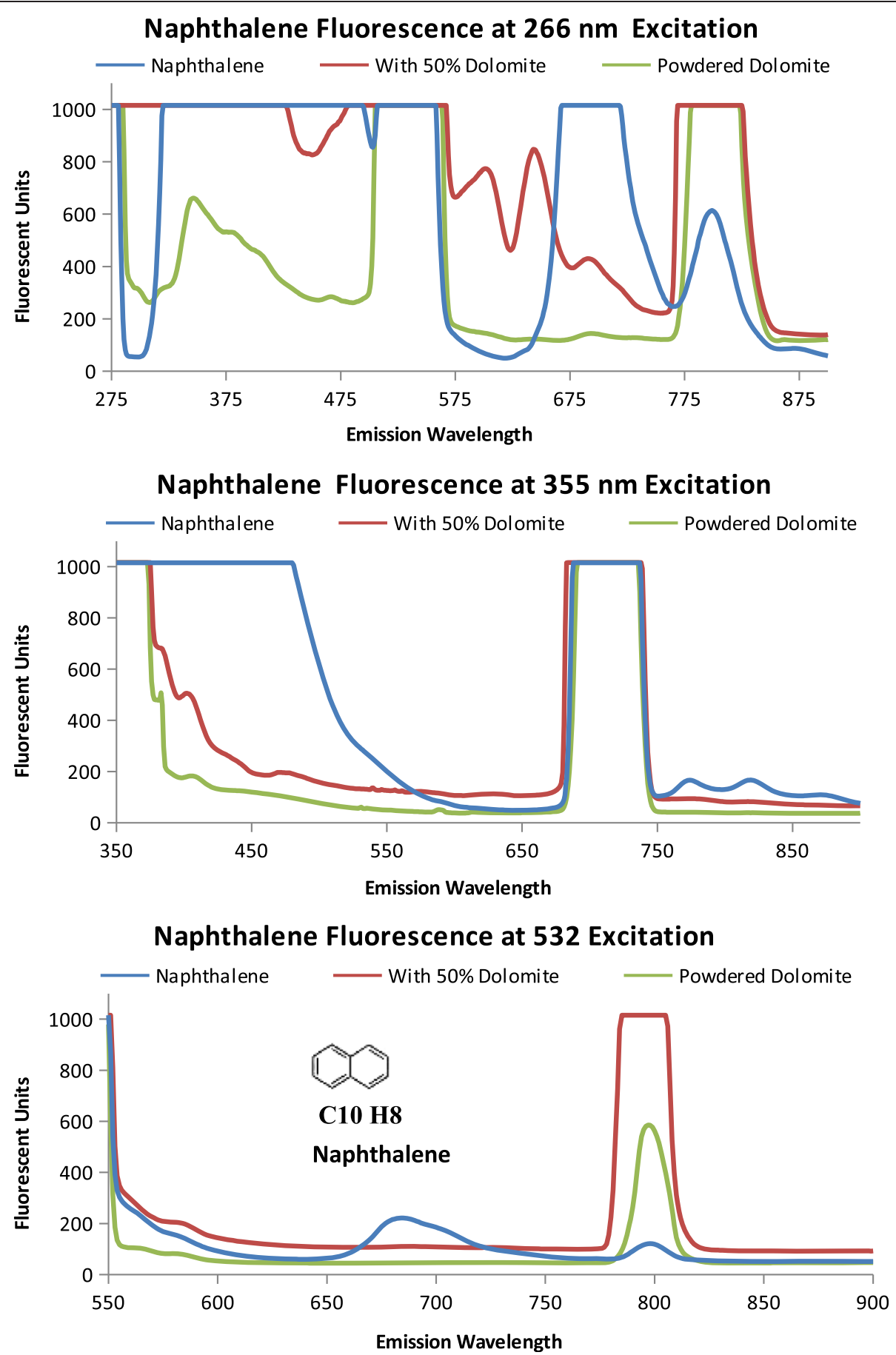

Figure 5 Naphthalene Fluorescence. Emission Spectra of naphthalene powdered dolomite, and a 50/50 by volume mixture of dolomite and naphthalene when excited at proposed excitation wavelengths ( $266 \mathrm{~nm}, 355 \mathrm{~nm}$, and $532 \mathrm{~nm}$ ). The molecular structure and formula is shown on the $532 \mathrm{~nm}$ emission graph.

candidates for organics on Mars. Storrie-Lombardi et al. [4] detected fluorescence, using a camera and filter wheel, of the three- ring-PAH anthracence, the four ring pyrene, and the five-ring perylene when excited at $365 \mathrm{~nm}$. The fluorescence characteristics of several PAH's are listed in
Table 1. Also listed are the fluorescent characteristics of the aromatic amino acids, phenylalanine, tyrosine, and tryptophan. In addition other biomolecules can be detected and identified using fluorescence as shown for ATP and NADH in Table 1. For a more detailed list 
of fluorescence of common biomolecules and detection of biomolecules by fluorescence refer to the Additional file 1 which is based on Smith et al. [29].

\section{Methods}

To ascertain fluorescence response at the constrained excitation wavelengths $(266 \mathrm{~nm}, 355 \mathrm{~nm}$, and $532 \mathrm{~nm})$, we measured the emission spectra for five PAHs (pyrene, phenanthrene, naphthalene, naphthol, and cresol) individually and when combined with a mineral in a 50/50 mixture by volume. The polycyclic aromatic hydrocarbons, (pyrene, phenanthrene, naphthalene, cresol, and naphthol), powdered dolomite, and $\mathrm{Ca}$ perchlorate were purchased from Sigma Aldrich (St. Louis, MO). Powdered dolomite was used as the mineral since it is a magnesium carbonate formed under aqueous conditions and possibly on the Martian surface [23].

Even though the primary task of the fluorescence instrument is to identify organics, the identification of minerals, especially water-associated minerals, would enhance the scientific value without adding to the cost.

To determine the feasibility of identifying minerals using the fluorescence instrument, emission spectra of several rock minerals known to be on the surface of Mars were generated for each of the three excitation wavelengths proposed for this instrument. Additionally emission spectra for rock minerals found at Mars Analog environments on Earth and potentially on Mars were measured. The rock mineral specimens (except for jarosite) were from the Utah State University Geology Department mineralogy and igneous petrology collection. Jarosite was collected from Panoche Valley in California by the research team.

All of the data presented in this paper were taken with a Shimadzu RF-1501 Fluorometer set to a resolution of $5 \mathrm{~nm}$. This instrument has a wavelength accuracy of $\pm 1.5 \mathrm{~nm}$ and a signal to noise ratio of $150: 1$ [38]. Our standard deviation based on triplicate sample measurements is less than $1 \%$, therefore we suggest the inhomogeneity of a sample could introduce a greater error than the that introduced by the method. A custom angled cuvet for powdered mixtures and a sample holder able to hold rocks was positioned in the fluorometer to obtain optimal emission spectra. Each specimen was excited by the fluorometer xenon flash lamp, at $266 \mathrm{~nm}, 355 \mathrm{~nm}$, and $532 \mathrm{~nm}$ and the emission spectra scanned from 220 $900 \mathrm{~nm}, 350-900 \mathrm{~nm}$, and 530-900 $\mathrm{nm}$ respectively.

\section{Results}

Fluorescence and quenching results for three polyaromatic hydrocarbons likely to be on Mars, pyrene, phenanthrene, and naphthalene, are shown in Figures 3, 4, and 5 and described in Table 2. The emission spectra for the individual PAH is compared with a $50 \%$ PAH $50 \%$ powdered dolomite by volume mixture and the spectrum for powdered dolomite.

The fluorescence from pyrene is shown in Figure 3. As shown in Figure 3A, when excited at $266 \mathrm{~nm}$ pyrene saturates the instrument detectors causing a flat line at the highest instrument readings (1000 Fluorescent units). The powdered dolomite and the 50/50 mixture of pyrene and dolomite have an emission peak at $340 \mathrm{~nm}$. This dolomite peak at $340 \mathrm{~nm}$ was also seen in the 50/50 mixture of pyrene and dolomite. The addition of the dolomite quenched the pyrene signal by lowering the fluorescent units to 600 for the $50 \%$ pyrene, $50 \%$ dolomite mixture compared with over 1000 fluorescent units for pyrene alone. Rather than fluorescence, the peaks from 498 to $532 \mathrm{~nm}$, and the peak from 770 to $810 \mathrm{~nm}$ are likely due to instrumentation setup and interactions between the excitation wavelength and the samples analyzed (dolomite and pyrene) which produces a resonance frequency at two times the excitation wavelength $(2 \lambda, 2 \times 266=532 \mathrm{~nm})$. Resonance frequencies can also occur at other intervals such as three times the excitation wavelength $(3 \lambda=798 \mathrm{~nm})$ as seen in the peak between 770 and $810 \mathrm{~nm}$. As seen in Figure 3B with the $355 \mathrm{~nm}$ excitation, the fluorescence emission detectors are saturated until $590 \mathrm{~nm}$ where the fluorescence sharply drops to around 500 fluorescent units and continues to reduce. The $710 \mathrm{~nm}$ emission peak (2 2 ) should be regarded as an artifact of the spectrometer grating instead of fluorescence. The $440 \mathrm{~nm}$ emission from the 50\%

Table 2 Summary of PAH spectrum characteristics for each of the polycyclic aromatic hydrocarbons shown above as measured for this study using a Shimadzu 1501 Fluorometer

\begin{tabular}{|c|c|c|c|c|c|c|}
\hline \multirow[t]{2}{*}{ PAH } & \multicolumn{2}{|c|}{$266 \mathrm{~nm}$ ex spectrum comparison } & \multicolumn{2}{|c|}{$355 \mathrm{~nm}$ ex spectrum comparison } & \multicolumn{2}{|c|}{$532 \mathrm{~nm}$ ex spectrum comparison } \\
\hline & Fluorescence(nm) & Quenching(nm) & Fluorescence (nm) & Quenching (nm) & Fluorescence $(\mathrm{nm})$ & Quenching (nm) \\
\hline Pyrene & 260 to 650 & & 355 to 590 & & 532 to 590 & \\
\hline Phenanthrene & 352 to 500,861 & 291 to 351,501 & 377 to 507,818 & 376 & 550 to 650 & \\
\hline \multirow[t]{2}{*}{ Naphthalene } & 315 to 557 & 291 to 314 & 355 to $506,766,818$ & & 683 & \\
\hline & 640 to 740 & 558 to 640 & & & & \\
\hline Naphthol & 321 to 400 & 291 to 320 & 410 & & & 790 \\
\hline Cresol & 380 & & 355 to 450,770 & 710 & & 790 \\
\hline
\end{tabular}



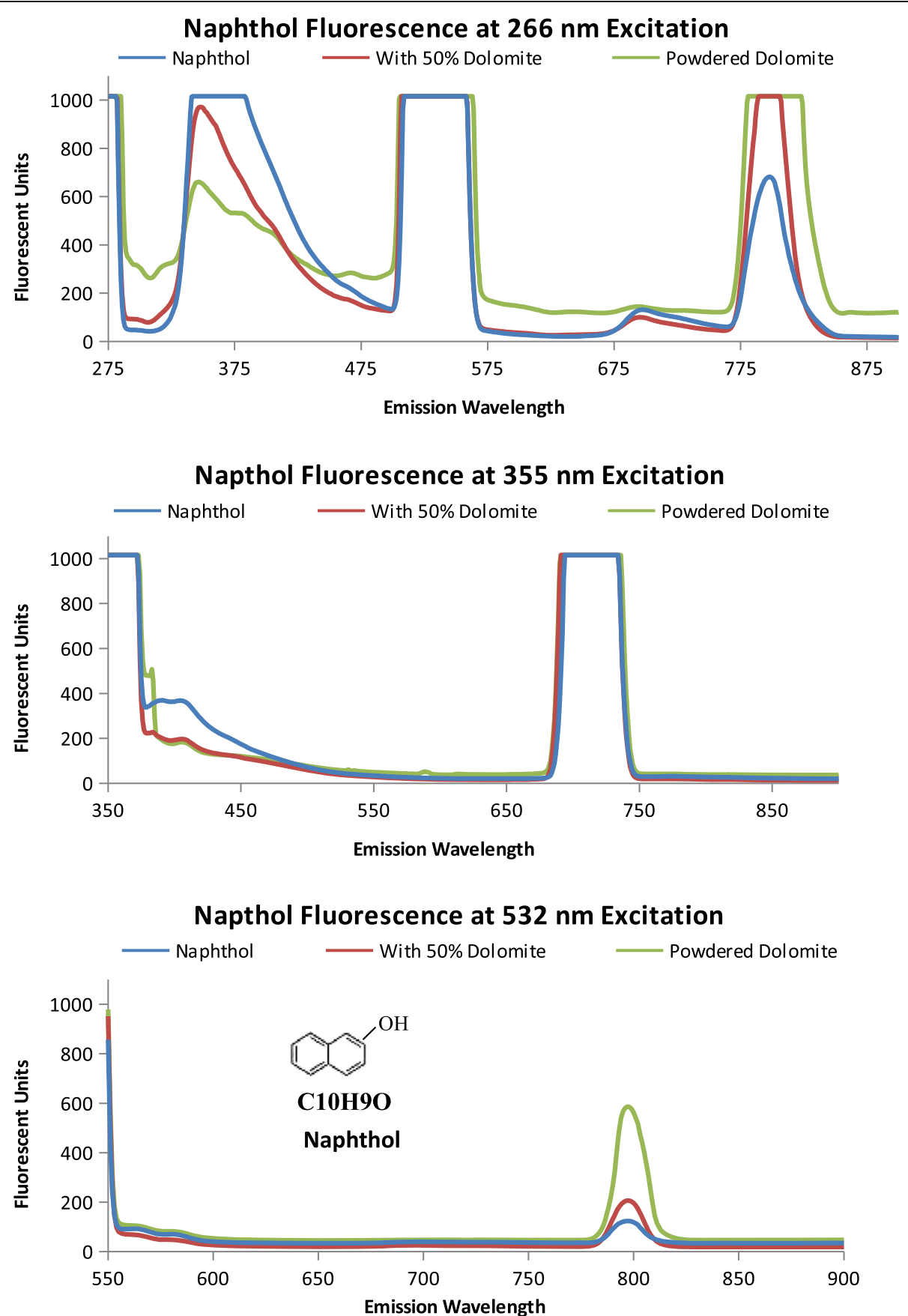

Figure 6 Napthol Fluorescence. Emission spectra of napthol, powdered dolomite, and a 50/50 mix when excited excitation wavelengths $266 \mathrm{~nm}, 355 \mathrm{~nm}$, and $532 \mathrm{~nm}$. The molecular structure and formula is shown on the $532 \mathrm{~nm}$ emission graph.

pyrene to $50 \%$ dolomite mixture by volume both enhances the dolomite peak at $440 \mathrm{~nm}$ and reduces the pyrene emission. For pyrene, as the excitation energy decreases, so does the variation in emission spectra (from graphs $3 \mathrm{~A}$ to $3 \mathrm{C})$. In $3 \mathrm{C}$, when excited at $532 \mathrm{~nm}$, pyrene has a small emission peak at $615 \mathrm{~nm}$. The peak at $790 \mathrm{~nm}(1.5 \lambda)$ frequency resonance is less for dolomite than for pyrene, and the $50 \%$ pyrene $50 \%$ dolomite by volume mixture.
In Figure 4 the three-ringed phenanthrene displays distinguishing emission spectra at each excitation wavelength. In Figure 4A, only phenanthrene has an emission peak at $861 \mathrm{~nm}(266 \mathrm{~nm}$ ex) and fluoresces from 351 to $500 \mathrm{~nm}$. At $355 \mathrm{~nm}$ excitation the $50 \%$ phenanthrene $50 \%$ dolomite by volume mixture and phenanthrene both have an emission peak at $818 \mathrm{~nm}$. When Phenanthrene is excited at $532 \mathrm{~nm}$, the $818 \mathrm{~nm}$ peak seen at 355 excitation disappears. 


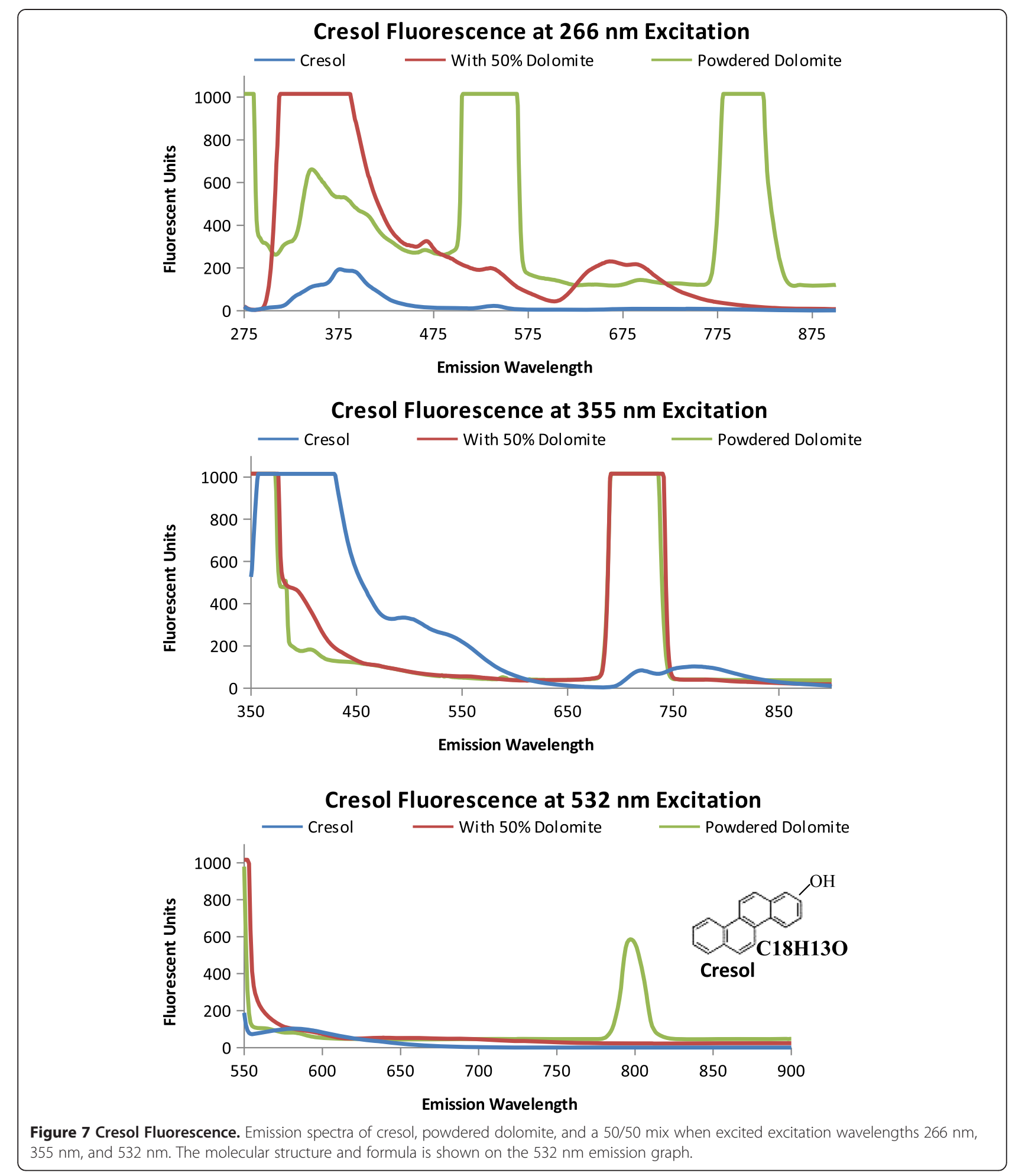

Naphthalene, as shown in Figure 5, also has an identifiable emission spectrum as pronounced by the $683 \mathrm{~nm}$ emission peak at $532 \mathrm{~nm}$ excitation. Naphthalene and Phenanthrene have similar spectrum profiles at $355 \mathrm{~nm}$ excitation, the higher peak intensity at $818 \mathrm{~nm}$ distinguishes Phenanthrene from Naphthalene.

The Martian surface contains superoxides [39] and therefore, oxidized polycyclic aromatic hydrocarbons 
(naphthol and cresol) were measured and compared to species without the addition of a hydroxyl group. As shown in Figure 6, naphthol, powdered dolomite, and the $50 \%$ naphthol, $50 \%$ dolomite by volume mixture have relatively similar emission spectrum. Some differences are the relative fluorescent units at $266 \mathrm{~nm}$ excitation and the naphthol emission peak at $355 \mathrm{~nm}$ excitation. Cresol, as shown in Figure 7, has a distinct emission spectrum for each excitation wavelength. At $266 \mathrm{~nm}$ excitation the cresol spectrum has a less fluorescence than dolomite. At $355 \mathrm{~nm}$ Cresol has an enhanced fluorescence followed from 380 to $440 \mathrm{~nm}$. At $532 \mathrm{~nm}$ the dolomite has an emission peak centered at $796 \mathrm{~nm}$. The hydroxyl radical alters the emission spectrum of the PAHs, by reducing the fluorescence as seen between the Naphthalene and Naphthol in Figure 8.

We measured minerals known to be on the surface of Mars. Non-contact or remote mineral identification would

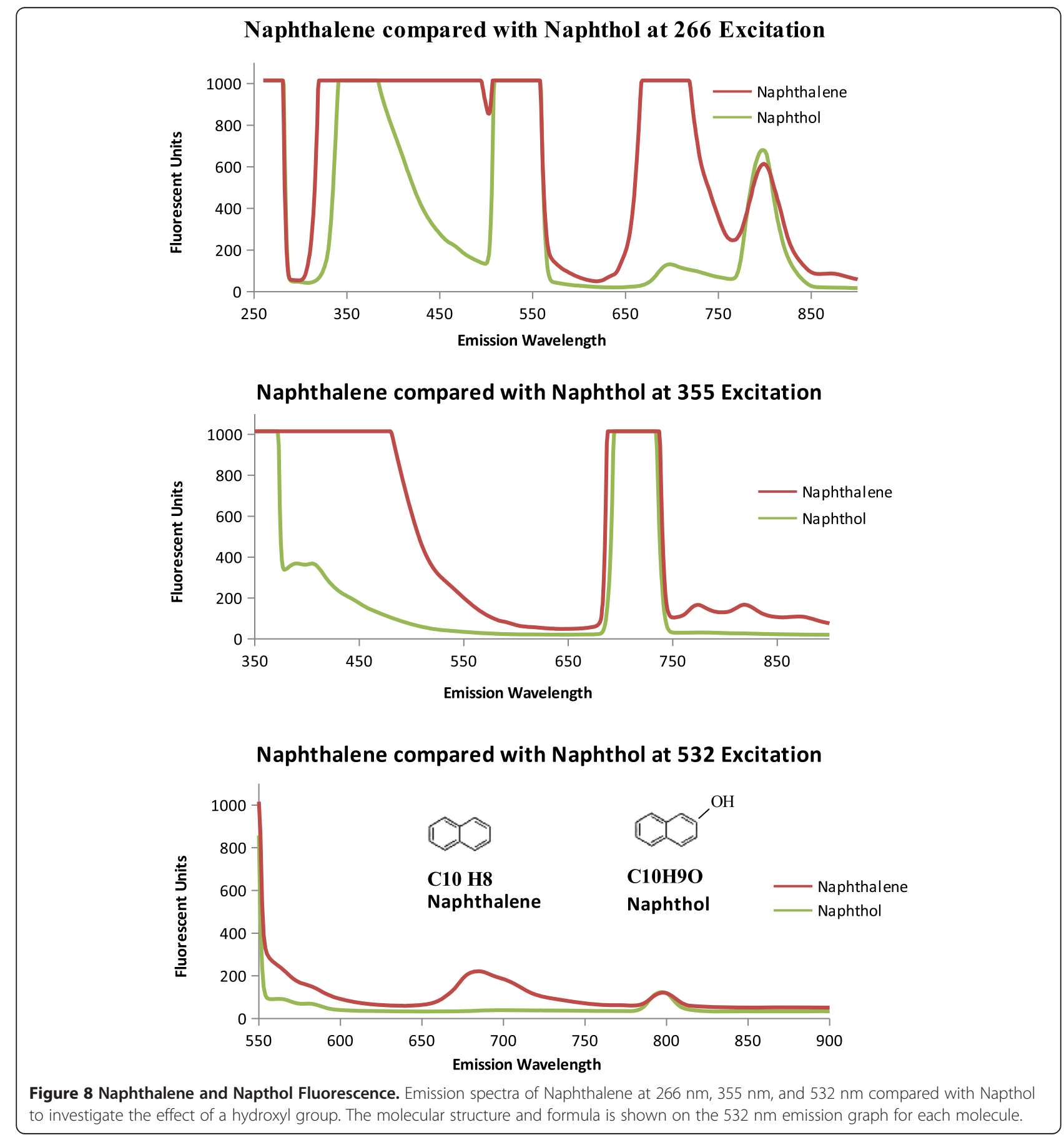


improve the scientific merit of the instrument. Also, as reported by Smith et al. [26] the detection of biomolecular fluorescence was influenced by mineral fluorescence. The data in Figure 9 shows the emission spectra of carbonates (calcite, limestone, travertine, rhodochrosite, siderite, and dolomite) and Figure 10 shows some water associated minerals (perchlorate, hematite (red and black), serpentine, and jarosite), known to be on the surface of Mars, when excited at $266 \mathrm{~nm}, 355 \mathrm{~nm}$, and $532 \mathrm{~nm}$. The portion of the spectra graphed is from the tail end of the excitation peak to the beginning of the $2 \lambda$ resonance fluorescence peak. Fluorescence beyond the $2 \lambda$ peak is unexpected due to the large Stokes shift and lower energy output. At $266 \mathrm{~nm}$ excitation rhodochrosite, siderite, hematite, and perchlorate have

\section{Carbonate Fluorescence at $\mathbf{2 6 6} \mathbf{~ n m}$ Excitation}

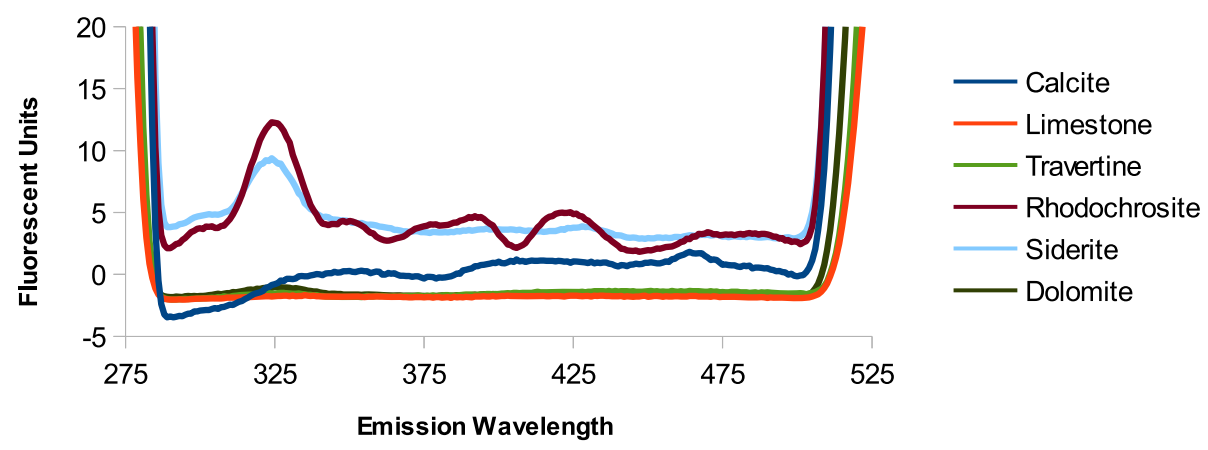

Carbonate Fluorescence at 355 nm Excitation

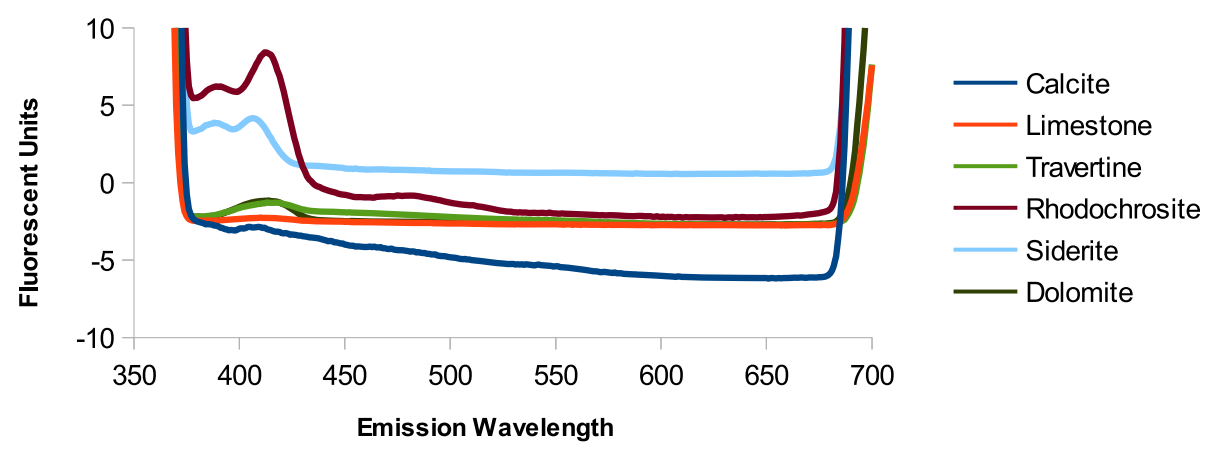

Carbonate Fluorescence at $\mathbf{5 3 2} \mathbf{n m}$ Excitation

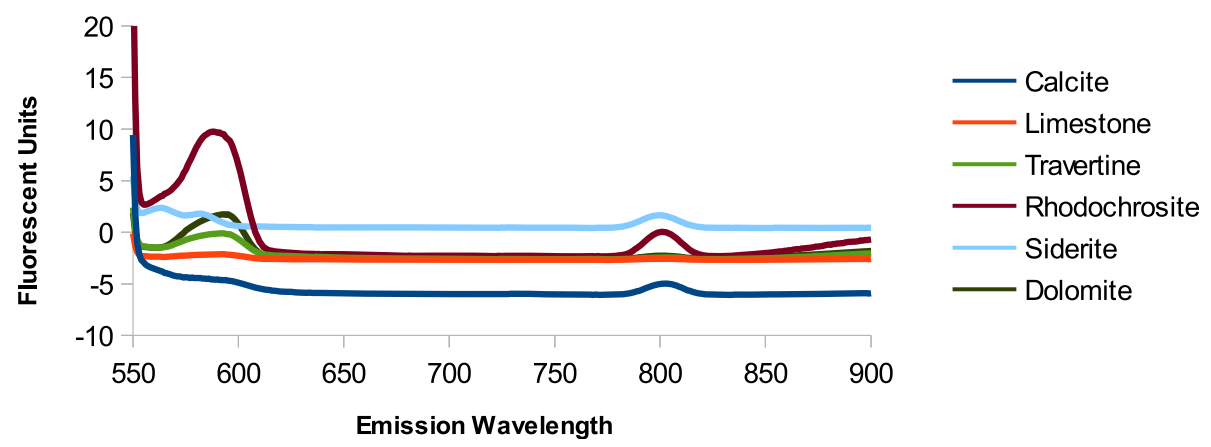

Figure 9 Carbonate Fluorescence. The spectrum on the left side of the graph is the tail end of the excitation peak. The rising spectrum on the right side of the graph is the beginning of the $2 \lambda$ peak. The $2 \lambda$ emission peak is an artifact of the grating within the Shimadzu Fluorometer and is not likely due to mineral fluorescence. Furthermore a $1.5 \lambda$ emission peak can be seen for the carbonates. This also is likely due to the instrument conditions rather than mineral fluorescence. 


\section{Mars Mineral Fluorsecence at $266 \mathrm{~nm}$ Excitation}

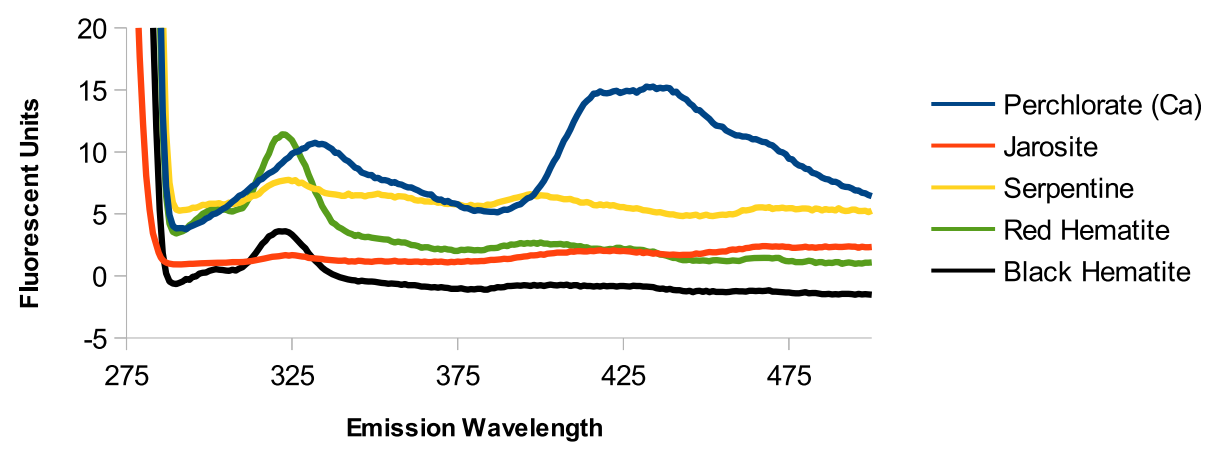

Mars Mineral Fluorescence at 355 nm Excitation

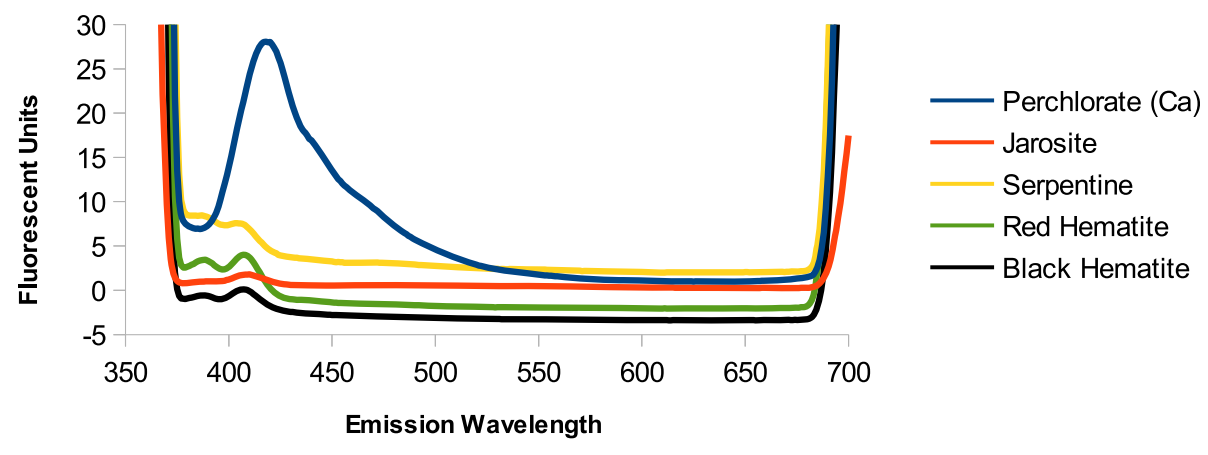

Mars Mineral Fluorescence at $\mathbf{5 3 2} \mathbf{~ n m}$ Excitation

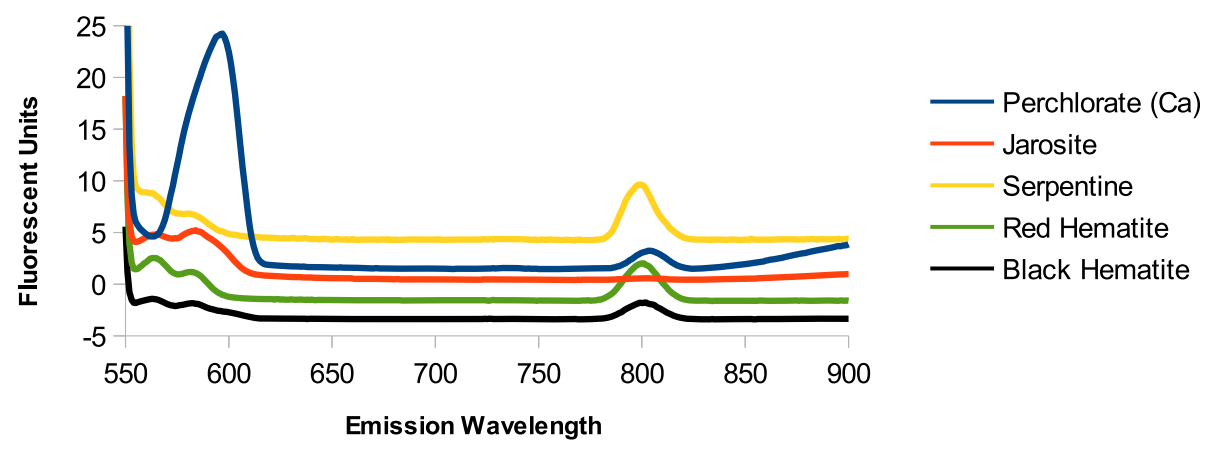

Figure 10 Fluorescence of Mars Minerals. The spectrum on the left side of the graph is the tail end of the excitation peak. The rising spectrum on the right side of the graph is the beginning of the $2 \lambda$ peak. The $2 \lambda$ emission peak is an artifact of the grating within the Shimadzu Fluorometer and is not likely due to mineral fluorescence. Furthermore a $1.5 \lambda$ emission peak can be seen for Ca perchlorate. This also is likely due to the instrument conditions rather than mineral fluorescence.

Table 3 Biomolecules, organics, and minerals detectable by fluorescence by measuring the emission spectra, when excited at the corresponding wavelength

\begin{tabular}{lll}
\hline $\mathbf{2 6 6} \mathbf{n m}$ excitation & $\mathbf{3 5 5} \mathbf{n m}$ excitation & $\mathbf{5 3 2} \mathbf{n m}$ excitation \\
\hline Adenosine Tri phosphate (ATP), Tryptophan, Tyrosine, & Dipicolinic acid, NADH, Phenanthrene, Naphthol, & Jarosite, Rhodochrosite, \\
$\begin{array}{l}\text { Pyrene, Phenanthrene, Naphthalene, Mg Perchlorate, } \\
\text { Hematite, Calcite, Siderite }\end{array}$ & $\begin{array}{l}\text { Cresol, Mg Perchlorate, Siderite, Rhodochrosite, } \\
\text { Hematite }\end{array}$ & Dolomite, Naphthalene \\
\hline
\end{tabular}


distinct emission peaks. At $355 \mathrm{~nm}$ excitation, most minerals have a small fluorescence peak between 400 and $410 \mathrm{~nm}$ with the exception of perchlorate which fluoresces about fifty times brighter at $538 \mathrm{~nm}$ and $589 \mathrm{~nm}$. At $532 \mathrm{~nm}$ the peaks are likely due to scattering of light or a grating effect at $1.5 \lambda$ rather than fluorescence, except for the small emission peak at $726 \mathrm{~nm}$ from perchlorate.

\section{Discussion}

The survey of PAH and mineral fluorescence performed in this study illustrates that the $1064 \mathrm{~nm}$ laser available in the flight ready ChemCam instrument modified with the addition of the three frequency multipliers $(266 \mathrm{~nm}$, $355 \mathrm{~nm}, 532 \mathrm{~nm}$ ) and band pass filters would provide an excellent site survey tool in near real time based on fluorescence measurements. Using mostly flight qualified hardware reduces the risk and cost associated with new instrumentation. A modified version of the ChemCam instrument described in this paper would be able to recognize biomolecules, PAHs, and minerals. Table 3 lists the material identifiable at the specified wavelengths.

With the operational flexibility of remote measurements, an outcrop could be surveyed a few meters away to avoid risks associated with movement. This greatly reduces the chance of mechanical failure from the rover getting stuck and expands the range of the target selection area. Future research will focus on expansion of the target database to include meteorites and tektites and on taking fluorescent measurements under conditions that are similar to those anticipated on Mars to determine the distances at which fluorescence detection is feasible.

\section{Conclusions}

We have developed a conceptual design for a fluorescencebased instrument for stand-off detection of organics on Mars. Our design is based on the technology developed for the ChemCam LIBS instrument that has been constructed for the Mars Science Laboratory mission. The key design change would be the addition of wavelength multiplexers to create higher harmonics of the $1064 \mathrm{~nm}$ laser that is presently on ChemCam. These lower wavelengths allow for fluorescence of both organic and mineral detection. To demonstrate this we have investigated the fluorescence properties at specific harmonic wavelengths of organics and minerals relevant to Mars. From this design work and data collection, our main conclusions are:

1) Fluorescence can be used to detect organics (PAH), and minerals that are expected to be on Mars.

2) The fluorescence instrument proposed is comprised almost entirely of flight-qualified Mars surface operational hardware reducing the risk and cost.
3) Feasibility of the instrument design offers a high scientific return (detection of organics) while expending minimal resources (time, development costs).

4) This instrument should be considered for the next mission to Mars as a site survey tool.

\section{Additional file}

Additional file 1: Table S1. Fluorometer Mineral List. Rocks analyzed using a custom rock holder in a Shimadzu 1501 fluorometer excited at 266 nm, 355 nm, and 532 nm. Figure S1. Varied Silica Content Emission Spectra. Igneous Rocks classified by silica content. Basalt has the lowest silica content, while Dacite has the highest. The middle silica content (Andesite) has the highest fluorescence. Figure S2. Sulfates Emission Spectra. Elemental sulfur compared with sulfate compounds. Figure S3. Oxides Emission Spectra. IImenite an TiO abundant at impact sites and on the Moon, compared with Pyrolusite a mineral that branches similar to trees, and Magnetite a known Mars mineral. Figure S4. Same

Composition Emission Spectra. Fluorescence from three minerals with the same composition, but formed under different conditions.

\section{Competing interests}

The authors declare that they have no competing interests.

\section{Authors' contributions}

HDS prepared the samples and carried out the fluorescence measurements, participated in discussions of the instrument design, and drafted the manuscript. CPM advised on all aspects of the ChemCam Instrument, participated in data analysis and discussion, and drafted a manuscript section. AGD drafted two figures for the manuscript, participated in fluorescence measurements and instrument design discussion. RCS advised on the all aspects of this research, assisted in data analysis and discussions. AJA advised on and provided the supplies for the PAH, and participated in data interpretation and discussions. PRG advised on the mineralogy aspects of this research and participated in data interpretation and discussions. All authors read and approved the final manuscript.

\section{Acknowledgment}

The authors would like to thank Dr. Charlie Miller of the USU Biological and Irrigation Engineering department for use of the Shimadzu 1501

Fluorometer. Dr. John Shervais and Marlon Jean of the USU Geology Department for access to the mineralogy and petrology collection, and to Dr. Chris Lloyd for helpful discussions. CPM was supported through funding from the NASA Planetary Protection Program. HDS is grateful for the NASA Graduate Student Research Program and the Planetary Protection Program for funding this research.

\section{Author details}

Department of Biological Engineering, Utah State University, Logan, UT, USA. ${ }^{2}$ NASA Ames Research Center, Space Science Division, Moffett Field, CA, USA. ${ }^{3}$ Desert Sensors, Logan, UT 84341, USA. ${ }^{4}$ Department of Biology, Utah State University, Logan, UT, USA. ${ }^{5}$ Department of Plants, Soils and Climate, Utah State University, Logan, UT, USA.

Received: 8 January 2014 Accepted: 11 June 2014 Published: 1 July 2014

\section{References}

1. Wiens RC, Maurice S, Barraclough B, Saccoccio M, Barkley WC, Bell JF, Bender S, Bernardin J, Blaney D, Blank J, Bouye M, Bridges N, Bultman N, Cais P, Clanton RC, Clark B, Clegg S, Cousin A, Cremers D, Cros A, DeFlores L, Delapp D, Dingler R, D'Uston C, Dyar MD, Elliott T, Enemark D, Fabre C, Flores M, Forni $\mathrm{O}$, et al: The ChemCam instruments on the Mars Science Laboratory (MSL) rover: body unit and combined system performance. Space Sci Rev 2012, 170(1-4):167-227.

2. Angel SM, Gomer NR, Sharma SK, McKay C: Remote Raman spectroscopy for planetary exploration: a review. App/ Spectrosc 2012, 66(2):137-150. 
3. Sharma SK, Misra AK, Lucey PG, Wiens RC, Clegg SM: Combined remote LIBS and Raman spectroscopy at $8.6 \mathrm{~m}$ of sulfur-containing minerals, and minerals coated with hematite or covered in basaltic dust. Spectrochim Acta A 2007, 68:1036-1045.

4. Storrie-Lombardi MC, Muller JP, Fisk MR, Griffiths AD, Coates AJ: Potiential for non-destructive astrochemistry using the ExoMars PanCam. Geophys Res Lett 2008, 35:L12201.

5. Hoge FE, Swift RN: Airborne simultaneous spectroscopic detection of laser-induced water Raman backscatter and fluorescence from chlorophyll a and other naturally occurring pigments. Appl Opt 1981, 20(18):3197-3205.

6. Allamandola $\amalg$, Sandford SA, Wopenka B: Interstellar polycyclic aromatic hydrocarbons and carbon in interplanetary dust particles and meteorites. Science 1987, 237(4810):56-59.

7. Chyba CF, Thomas PJ, Brookshaw L, Sagan C: Cometary delivery of organic molecules to the early Earth. Science 1990, 249(4967):366-373.

8. Flynn GJ: The delivery of organic matter from asteroids and comets to the early surface of Mars. Earth Moon Planet 1996, 72(1-3):469-474.

9. Hoge FE, Wright CW, Kana TM, Swift RN, Yungel JK: Spatial variability of oceanic phycoerythrin spectral types derived from airborne laser-induced fluorescence emissions. Appl Opt 1998, 37(21):4744-4749.

10. Karlitschek $P$, Lewitzka F, Bünting U, Niederkrüger M, Marowsky G: Detection of aromatic pollutants in the environment by using UV-laser-induced fluorescence. Appl Phys B 1998, 67(4):497-504.

11. Ehrenfreund $P$, Charnley SB: Organic molecules in the interstellar medium, comets, and meteorites: a voyage from dark clouds to the early Earth. Annu Rev Astron Astrophys 2000, 38(1):427-483.

12. Feldmann C, Jüstel $T$, Ronda CR, Schmidt PJ: Inorganic luminescent materials: 100 years of research and application. Adv Funct Mater 2003, 13(7):511-516

13. Sephton MA, Love GD, Watson JS, Verchovsky AB, Wright IP, Snape CE, Gilmour l: Hydropyrolysis of insoluble carbonaceous matter in the Murchison meteorite: new insights into its macromolecular structure. Geochim Cosmochim Acta 2004, 68(6):1385-1393.

14. Gabrecht T: Clinical Fluorescence Spectroscopy And Imaging For The Detection Of Early Carcinoma By Autofluorescence Bronchoscopy And The Study Of The Protoporphyrin Ix Pharmacokinetics In The Endometrium; 2006. Doctorate Thesis École Polytechnique Fédérale De Lausanne.

15. Dartnell LR, Storrie-Lombardi MC, Ward JM: Complete fluorescent fingerprints of extremophilic and photosynthetic microbes. Int J Astrobiol 2010, 9(4):245-257.

16. Sattler B, Storrie-Lombardi M, Foreman C, Tilg M, Psenner R: Laser-induced fluorescence emission (LIFE) from Lake Fryxell (Antarctica) cryoconites. Ann Glaciol 2010, 51(56):145-152.

17. Cabrol NA, Cabrol NA, Wettergreen D, Warren-Rhodes K, Grin EA, Moersch J, Chong Diaz G, Cockell CS, Coppin P, Demergasso C, Dohm J, Ernst L, Fisher G, Glasgow J, Hardgrove C, Hock AN, Jonak D, Marinangeli L, Edwin Minkley E, Ori GG, Piatek J, Pudenz E, Smith T, Stubbs K, Thomas G, Thompson D, Waggoner A, Wagner M, Weinstein S, Wyatt M: Life in the Atacama: searching for life with rovers (science overview). J Geophys Res 2007, 112:G04S02. doi:10.1029/2006JG000298.

18. Bay RC, Bramall NE, Price PB: Search for microbes and biogenic compounds in polar ice using fluorescence. In Life in Ancient Ice. Edited by Castello JD, Rogers SO. New Jersey, USA: Princeton University Press; 2005:268-276.

19. Storrie-Lombardi MC, Sattler B: Laser-induced fluorescence emission (LIFE): in-situ nondestructive detection of microbial life in the ice covers of Antarctic lakes. Astrobiology 2009, 9(7):659-672.

20. Bhartia R, Salas EC, Hug WF, Reid RD, Lane AL, Edwards KJ, Nealson KH: Label-free bacterial imaging with deep UV laser induced native fluorescence. Appl Environ Microbiol 2010, 76(21):7231-7237.

21. Smith HD, Powers LS, Duncan AG, Neary PL, Lloyd CR, Anderson AJ, Sims RC, McKay CP: In-situ microbial detection in Mojave desert soil using native fluorescence. Astrobiology 2012, 12(3):247-257.

22. Bozlee BJ, Misra AK, Sharma SK, Ingram M: Remote raman and fluorescence studies of mineral samples. Spectrochim Acta A 2005, 61:2342-2348.

23. Ming DW, Archer PD Jr, Glavin DP, Eigenbrode JL, Franz HB, Sutter $B$ Brunner AE, Stern JC, Freissinet C, McAdam AC, Mahaffy PR, Cabane M, Coll P, Campbell JL, Atreya SK, Niles PB, Bell JF 3rd, Bish DL, Brinckerhoff WB, Buch A, Conrad PG, Des Marais DJ, Ehlmann BL, Fairén AG, Farley K, Flesch GJ, Francois
P, Gellert R, Grant JA, Grotzinger JP, et al: Volatile and organic compositions of sedimentary rocks in Yellowknife Bay, Gale Crater, Mars. Science 2013, 342:1245267-1-r. Published online 9 December. doi:10.1126/science.1245267.

24. Smith PH, Tamppari LK, Arvidson RE, Bass D, Blaney D, Boynton W, Carswell A, Catling DC, Clark BC, Duck T, DeJong E, Fisher D, Goetz W, Gunnlaugsson HP, Hecht MH, Hipkin V, Hoffman J, Hviid SF, Keller HU, Kounaves SP, Lange CF, Lemmon MT, Madsen MB, Markiweicz WJ, Marshall J, McKay CP, Mellon MT, Ming DW, Morris RV, Pike WT, et al: $\mathrm{H}_{2} \mathrm{O}$ at the Pheonix landing site. Science 2009, 325:58-61.

25. Griffiths AD, Coates AJ, Josset $J$, Paar $G$, Hofmann B, Rueffer P, Pillinger $C T$, Sims MR, Pullan D: The Beagle 2 stereo camera system: scientific objectives and design characteristics. Planet Space Sci 2005, 53(14-15):1466-1482.

26. Griffiths AD, Coates AJ, Jaumann R, Michaelis H, Paar G, Barnes D, Josset JL, Team PC: Context for the ESA ExoMars rover: the Panoramic Camera (PanCam) instrument. Int J Astrobiol 2006, 5(3):269.

27. McKay DS, Gibson EK, Thomas-Keprta KL, Hojatollah V, Romanek CS, Clemett SJ, Chillier XDF, Maechling CR, Zare RN: Search for past life on Mars: possible relic biogenic activity in Martian meteorite ALH84001. Science 1996, 273:924-930.

28. Kuan YJ, Charnley SB, Huang HC, Tseng WI, Zbigniew K: Interstellar glycine. Astrophys J 2003, 593(2):848-867. doi:10.1086/375637.

29. Smith HD, Powers LS, Duncan AG, Neary PL, Anderson AJ, Sims RC, McKay CP. In Situ Microbial Detection in the Mojave Desert Using Native Fluorescence; 2010. Utah State University, Department of Biological Engineering, PhD Dissertation.

30. Katayama M, Matsudaa Y, Shimokawaa Kl, Tanabea S, Kanekob S, Harac I, Satoc $\mathrm{H}$ : Simultaneous determination of six adenyl purines in human plasma by high-performance liquid chromatography with fluorescence derivatization. J Chromatogr B Biomed Sci Appl 2001, 760(1):53-58

31. Seaver M: Size and fluorescence measurements for field detection of biological aerosols. Aerosol Sci Technol 1999, 30(2):174-185.

32. Richards-Kortum R, Sevick-Muraca E: Quantitative optical spectroscopy for tissue diagnosis. Annu Rev Phys Chem 1996, 47:555-606.

33. Nevin A, Cather S, Anglos D, Fotakis C: Laser-induced fluorescence analysis of protein-based binding media. In Lasers in the Conservation of Artworks, Volume 116. Edited by Nimrichter J, Kautek W, Schreiner M.: Springer Proceedings in Physics; 2007:399-406.

34. Alimova A, Katz A, Savage HE, Shah M, Minko G, Will DE, Rosen RB, McCormick SA, Alfano RR: Native fluorescence and excitation spectroscopic changes in Bacillus subtilis and Staphylococcus aureus bacteria subjected to conditions of starvation. Appl Opt 2003, 42:19.

35. Kuijt J, García-Ruiz C, Stroomberg GJ, Marina ML, Ariese F, Brinkman UAT, Gooijer C: Laser-induced fluorescence detection at $266 \mathrm{~nm}$ in capillary electrophoresis polycyclic aromatic hydrocarbon metabolites in biota. J Chromatogr A 2001, 907:291-299.

36. Pujari SR, Bosale PN, Rao PMR: Sensitized monomer fluorescence and excitation energy transfer in perlyene-doped phenanthrene in crystalline and polymer matrix. Mater Res Bull 2002, 37:439-448.

37. Wilson JN, Gao J, Koo ET: Oligodeoxyfluorosides: strong sequence dependence of fluorescence emission. Tetrahedron 2007, 63(17):3427-3433.

38. Shimadzu Corporation: RF-1501 Spectrophotometer; 2003.

39. Klein HP: The Viking biological investigation: general aspects. J Geophys Res 1977, 82(28):4677-4680

doi:10.1186/1754-1611-8-16

Cite this article as: Smith et al:: An instrument design for non-contact detection of biomolecules and minerals on Mars using fluorescence. Journal of Biological Engineering 2014 8:16. 